\title{
Neonatal Chlamydia Conjunctivitis
}

National Cancer Institute

\section{Source}

National Cancer Institute. Neonatal Chlamydia Conjunctivitis. NCI Thesaurus. Code

C116817.

Inflammation of the conjunctiva in a newborn due to Chlamydia trachomatis which was acquired during labor and delivery. 